Editorial

\title{
Antimicrobial drug resistance threat: our duty towards future generations
}

Keiji Fukuda ${ }^{1}$

Since their availability in the 1940s, antimicrobial drugs have been a miracle. For example, penicillin reduced death rates among patients with pneumonia and bacteraemia from approximately $90 \%$ to $10 \%$. Seventy years later, however, increasing levels of antimicrobial resistance (AMR) on all continents is endangering the prevention and treatment of infections ranging from the common to the life-threatening ones which disproportionately affect the poor, such as tuberculosis, malaria and HIV. The emergence of new resistance mechanisms is making some Gramnegative infections virtually untreatable, while other community-acquired bacterial infections, including those affecting children, are becoming progressively more difficult to treat. In January 2013 the World Economic Forum warned that antibiotic resistance was one of the major global risks humanity needs to address [1]. Recently, the United Kingdom's Chief Medical Officer recently called AMR a "catastrophic threat," stating that unless resistance is curbed, "We will find ourselves in a health system not dissimilar to the early 19 th century" in which organ transplants, cancer chemotherapy, joint replacements and even minor surgeries become life-threatening [2]. In essence, AMR is a situation in which the simultaneous pandemic spread of multiple drug-resistant organisms is fast outpacing available solutions and is creating a major global public health threat.

The underlying challenge is that the inherent capacity of microbes to develop resistance to antimicrobial drugs is being fuelledby the widespreaduse, and misuse, of such agents in all regions of the world in both health and agricultural practices [3]. Currently, over $80 \%$ of the antimicrobial drugs (including penicillins, tetracyclines, macrolides, cephalosporins) sold in the United States of America are used in agriculture. About $90 \%$ of the antimicrobial drugs used for animals are added to their feed or drinking-water, primarily for growth promotion and feed efficiency [4]. Moreover, environmental contamination by antimicrobials from agricultural, medical and pharmaceutical industry sources is driving the evolution of a pool of resistant bacteria that can spread globally $[5,6]$ underscoring the need for a broad multisectoral "one health" approach:[7].

The impact of AMR on lives, health systems and economies is already considerable and will continue to grow. For example, hospital-acquired antibioticresistant infections contribute to significant numbers of deaths every year while losses to gross domestic product have been estimated at $0.4 \%$ to $1.6 \%$ [1].

Many critical actions are needed: However, of paramount importance is to immediately move beyond current perceptions of the issues as "technical" or "medical" in nature. AMR poses a broad social challenge with serious health security implications. Now is the time for key stakeholders, especially governments and sectors such as industry, agriculture and health, to become fully engaged.

\section{References}

1. Global Risks Report 2013. Geneva, World Economic Forum, 2013. (http://www3.weforum.org/docs/WEF_GlobalRisks_ Report_2013.pdf, accessed 26 March, 2013).

2. Chief Medical Officer Dame Sally Davies: Resistance to antibiotics risks health "catastrophe" to rank with terrorism and climate change. The Independent, $11 \mathrm{March}$ 2013 (http://www.independent.co.uk/news/science/ chief-medical-officer-dame-sally-davies-resistance-toantibiotics-risks-health-catastrophe-to-rank-with-terrorismand-climate-change-8528442.html, accessed 26 March 2013).

3. The world medicines situation 2011, 3rd ed. Geneva, World Health Organization, 2011 (http://www.who.int/nha/docs/ world_medicine_situation.pdf, accessed 26 March 2013).

4. 2010 summary report on antimicrobials sold or distributed for use in food-producing animals. Silver Spring, MD, US Food and
Drug Administration, 2010 (http://www.fda.gov/downloads/ Forlndustry/UserFees/AnimalDrugUserFeeActADUFA/ UCM277657.pdf, accessed 7 May 2013).

5. Sjölund $\mathrm{M}$ et al. Dissemination of multidrug-resistant bacteria into the Arctic. Emerging Infectious Diseases, 2008, 14(1):70-72.

6. Hernández J et al. Human-associated extended-spectrum $\beta$-lactamase in the Antarctic. Applied and Environmental Microbiology, 2012, 78(6):2056-2058 (http://aem.asm.org/ content/78/6/2056.long, accessed 7 May 2013).

7. FAO/OIE/WHO/UNSIC. High-level technical meeting to address health risks at the human-animal-ecosystems interfaces. Mexico City, Mexico, 15-17 November 2011 (http://apps.who. int/iris/bitstream/10665/78100/1/9789241504676_eng.pdf, accessed 7 May 2013). 